\title{
Antioxidant and Antibacterial Effects of Pollen Extracts on Human Multidrug-Resistant Pathogenic Bacteria
}

\author{
Meryem Bakour $\mathbb{D}^{1},{ }^{1}$ Hassan Laaroussi $\left(\mathbb{D},{ }^{1}\right.$ Driss Ousaaid $\mathbb{D}^{1},{ }^{1}$ Bouchra Oumokhtar, ${ }^{2}$ \\ and Badiaa Lyoussi (iD 1 \\ ${ }^{1}$ Laboratory of Natural Substances Pharmacology Environment Modeling Health and Quality of Life (SNAMOPEQ), \\ Faculty of Sciences Dhar El Mahraz, University Sidi Mohamed Ben Abdellah, 30000 Fez, Morocco \\ ${ }^{2}$ Laboratory of Microbiology, Faculty of Medicine and Pharmacy, University Sidi Mohamed Ben Abdallah, 30000 Fez, Morocco
}

Correspondence should be addressed to Badiaa Lyoussi; lyoussi@gmail.com

Received 25 January 2021; Revised 10 May 2021; Accepted 22 June 2021; Published 1 July 2021

Academic Editor: Flora V. Romeo

Copyright ( ) 2021 Meryem Bakour et al. This is an open access article distributed under the Creative Commons Attribution License, which permits unrestricted use, distribution, and reproduction in any medium, provided the original work is properly cited.

\begin{abstract}
The present work was designed to search the possible antibacterial effect of the ethanolic extract of pollens from six botanical origins, Punica granatum, Quercus ilex, Centaurium erythraea, Coriandrum sativum, Ruta graveolens, and Citrus aurantium, against multidrug pathogenic bacteria, Escherichia coli, Pseudomonas aeruginosa, Enterobacter cloacae, Acinetobacter baumannii, Klebsiella pneumoniae, and Staphylococcus aureus. The content of phenolic compounds, flavones, and flavonols was measured. The antioxidant activities were evaluated using four assays: total antioxidant capacity, DPPH, ABTS, and reducing power. Antibacterial activity was studied using the agar disk diffusion method, and the MIC and MBC were determined. Results obtained showed a positive correlation between the antioxidant content of pollen extracts and the antibacterial capacity, Punica granatum and Quercus ilex pollen extracts were the most efficient against Gram-positive and Gram-negative bacteria, and Centaurium erythraea, Coriandrum sativum, and Ruta graveolens had a moderate effect, while Citrus aurantium had no antibacterial effect. It is concluded that pollens can be a good source of bioactive molecules that exhibit potent antioxidant effects and strong antibacterial activities.
\end{abstract}

\section{Introduction}

The biggest challenge of public health in recent years is antibiotic resistance. This phenomenon is caused by the unreasonable use of antibacterial drugs; it aggravates the impact of microbial infections on public health. The search for alternative therapeutic strategies by discovering other antibacterial agents has attracted many scientists [1].

Recently, research studies on beehive products, especially honey and bee pollen, have attracted much attention due to their richness in bioactive molecules and their pharmacological effects $[2,3]$. On the contrary, pollens are essential for honey bees. They are the main source of proteins, fats, minerals, and vitamins necessary for their nutrition. The honey composition depends strongly on the type of flowers foraged by bees [4].
Pollens contain a mixture of essential nutrients used by the plant to boost their growth and development [5]. Hence, the chemical composition of pollen is mainly determined by its plant species. Their chemical compounds may have different biological activities such as antitumoral, antidiabetic, and antimicrobial effects [6-8].

Many studies indicate that polyphenol compounds and, especially, flavonoids are among secondary metabolites that have many biological activities, such as antioxidant [9], anticancer [10], and antibacterial activities [11].

During the present investigation, pollens from six plants were selected: Punica granatum, Quercus ilex, Centaurium erythraea, Coriandrum sativum, Ruta graveolens, and Citrus aurantium. Based on the literature, these plants are widely used in traditional medicine. They have significant biological activities such as the antimicrobial effect showed by Punica 
granatum [12], the control of the gastrointestinal disorders and dietary uptake of glucose at the intestinal tract found by Quercus ilex [13], the protective effect against oxidative stress of Centaurium erythraea [14], the antinociceptive and antiedema properties of Coriandrum sativum [15], the protective effect of Ruta graveolens against gastric ulcer [16], and hepatoprotective effect of Citrus aurantium [17].

The main goal of this paper would help to highlight the antioxidant potential and antibacterial effect of pollens obtained from five plant families: Fagaceae, Gentianaceae, Punicaceae, Rutaceae, and Apiaceae. Polyphenol, flavone, and flavonol contents were determined, and the antioxidant activities were performed by four tests: total antioxidant capacity, DPPH, ABTS, and reducing power. In contrast, the antibacterial test was evaluated against six bacterial strains: Escherichia coli, Pseudomonas aeruginosa, Enterobacter cloacae, Acinetobacter baumannii, Klebsiella pneumoniae, and Staphylococcus aureus.

This is the first report on the antioxidant content and antibacterial activity of pollen of these selected plants.

\section{Materials and Methods}

2.1. Pollen Samples. Pollens of Quercus ilex (Fagaceae), Centaurium erythraea (Gentianaceae), Punica granatum (Punicaceae), Citrus aurantium (Rutaceae), Ruta graveolens (Rutaceae), and Coriandrum sativum (Apiaceae) were collected from the city of Fez (latitude: $34^{\circ} 01^{\prime} 59^{\prime \prime} \mathrm{N}$; longitude: $5^{\circ} 00^{\prime} 01^{\prime \prime} \mathrm{W}$; altitude: $\left.406 \mathrm{~m}\right)$, Morocco.

2.2. Pollen Extracts. $1 \mathrm{~g}$ of pollen was extracted using ethanol (50\%) for one week, sonicated for $5 \mathrm{~min}$, and centrifuged at $2000 \times \mathrm{g}$ and $20^{\circ} \mathrm{C}$; the obtained supernatants were filtered through a $0.45 \mu \mathrm{m}$ filter paper. The extracts were kept at $-20^{\circ} \mathrm{C}$ until use.

2.3. Total Phenolic Content. The quantification of phenolic compounds was estimated using the protocol of Mărghitaş et al. [18]. In brief, $100 \mu \mathrm{L}$ of pollen extracts was mixed with $500 \mu \mathrm{L}$ of Folin-Ciocalteu reagent $(0.2 \mathrm{~N})$ and $400 \mu \mathrm{L}$ of sodium carbonate solution (7.5\%). The mixture was kept in the dark for two hours, and then the absorbance was measured at $760 \mathrm{~nm}$ (PerkinElmer Lambda $40 \mathrm{UV} / \mathrm{Vis}$ spectrophotometer). Gallic acid was used as a standard to achieve the calibration curve $\left(R^{2}=0.996\right)$. The results were expressed in mg equivalent of gallic acid per gram of pollen (mgGAE/g). Tests were carried out in triplicate.

2.4. Flavone/Flavonol Content. Flavone/flavonol content was determined according to the method of Miguel et al. [19]. A mixture of $300 \mu \mathrm{L}$ of $\mathrm{Al}_{2} \mathrm{Cl}_{3}(20 \%)$ and $300 \mu \mathrm{L}$ of each ethanolic pollen extract was incubated for $1 \mathrm{~h}$. Then, the absorbance was measured at $420 \mathrm{~nm}$ with a PerkinElmer Lambda $40 \mathrm{UV} / \mathrm{V}$ is spectrophotometer. Quercetin (0.261 to $1.423 \mathrm{mg} / \mathrm{mL}$ ) was used as a standard to achieve the calibration curve $\left(R^{2}=0.997\right)$. The results were expressed in milligram of quercetin equivalent (QE) per gram of pollen (mg QE/g). The tests were carried out in triplicate.

2.5. Total Antioxidant Capacity by the Phosphomolybdenum Assay. The phosphomolybdenum assay was used for the determination of the total antioxidant capacity (TAC) according to the method of Zengin et al. [20]. About $25 \mu \mathrm{L}$ of each ethanolic pollen extract or ascorbic acid (used as the standard) was mixed with $1 \mathrm{~mL}$ of reagent solution $(6 \mathrm{M}$ of sulfuric acid, $28 \mathrm{mM}$ of sodium phosphate, and $4 \mathrm{mM}$ of ammonium molybdate). Then, after $90 \mathrm{~min}$ of incubation in a water bath at $95^{\circ} \mathrm{C}$, the absorbance of the solution was measured at $695 \mathrm{~nm}$ against the control with a PerkinElmer Lambda $40 \mathrm{UV} / \mathrm{Vis}$ spectrophotometer. The results were expressed in milligrams of ascorbic acid equivalent (AAE) per gram of pollen (mg AAE/g). The tests were carried out in triplicate.

2.6. Free Radical Scavenging Activity (DPPH). Free radical scavenging activity (DPPH assay) was measured according to the method described by Miguel et al. [19]. $75 \mu \mathrm{L}$ of different dilutions of each pollen extract or BHT (used as the positive control) was added to $825 \mu \mathrm{L}$ of $\mathrm{DPPH}$ solution (63.4 $\mu \mathrm{M}$, prepared in ethanol), the reaction was carried out in the dark for one hour, and the absorbance was taken at $517 \mathrm{~nm}$ with a PerkinElmer Lambda $40 \mathrm{UV} / \mathrm{Vis}$ spectrophotometer. The tests were carried out in triplicate. The percentage of the DPPH radical scavenging inhibition was estimated using the following equation:

$$
\% \text { inhibition }=\frac{\text { Abs control }- \text { Abs sample }}{\text { Abs control }} \times 100 \text {. }
$$

The concentration of each pollen sample required to scavenge $50 \%$ of $\mathrm{DPPH}\left(\mathrm{IC}_{50}\right)$ was determined graphically using the curve plotted by the percentage of DPPH inhibition as a function of the sample concentration. The $\mathrm{IC}_{50}$ values were expressed in $\mu \mathrm{g} / \mathrm{mL}$.

2.7. Azino-bis(3-ethylbenzothiazoline-6-sulphonic Acid) (ABTS) Free Radical Scavenging Activity. The ABTS assay was determined following the method of Silva et al. [21]. In brief, $75 \mu \mathrm{L}$ of different dilutions of each ethanolic pollen extract or BHT (used as the positive control) was added to $825 \mu \mathrm{L}$ of ABTS radical cation solution. The resulting solutions were incubated in the dark for $6 \mathrm{~min}$ at room temperature, and the intensity of the produced color was measured at $734 \mathrm{~nm}$ by UV/Vis spectrophotometer. The percentage of ABTS radical cation inhibition was calculated using equation (1). The $\mathrm{IC}_{50}$ values were determined graphically and expressed in $\mu \mathrm{g} / \mathrm{mL}$.

2.8. Reducing Power (RP). The reducing power was carried out according to the method of Padmanabhan and Jangle [22]. A mixture of $50 \mu \mathrm{L}$ of the ethanolic pollen extract, $200 \mu \mathrm{L}$ of $0.2 \mathrm{M}$ sodium phosphate buffer $(\mathrm{pH} 6.6)$, and $200 \mu \mathrm{L}$ of $1 \%$ potassium ferricyanide was incubated at $50^{\circ} \mathrm{C}$ for $20 \mathrm{~min}$, and then $200 \mu \mathrm{L}$ of $10 \%$ trichloroacetic acid was 
added and immediately mixed with $600 \mu \mathrm{L}$ of distilled water and $120 \mu \mathrm{L}$ of $0.1 \%$ ferric chloride. The mixture's absorbance was measured at $700 \mathrm{~nm}$ with a PerkinElmer Lambda 40 $\mathrm{UV} / \mathrm{Vis}$ spectrophotometer. Ascorbic acid was used as a positive control. A graph was plotted using the absorbance at $700 \mathrm{~nm}$ against the sample concentration. The results were represented as the concentration of the pollen extract providing 0.5 of absorbance $\left(\mathrm{EC}_{50}\right)$. The $\mathrm{EC}_{50}$ values were expressed in $\mu \mathrm{g} / \mathrm{mL}$.

\subsection{Antibacterial Activity}

2.9.1. Bacterial Strains. The study was performed on Grampositive bacteria, Staphylococcus aureus (20s1), and Gramnegative bacteria, Acinetobacter baumannii (118e1), Enterobacter cloacae (57e2/n), Escherichia coli (7), Klebsiella pneumoniae (6), and Pseudomonas aeruginosa (8e1); all bacterial strains were collected from human specimens and obtained from the Laboratory of Microbiology, Faculty of Medicine and Pharmacy Fez. Bacterial strains were selected based on their resistance to antibiotics.

2.9.2. Sensitivity Test. (1) Agar Disk Diffusion Method. The antibacterial activity of pollen extracts was studied using the disk diffusion method [23]; $20 \mathrm{ml}$ of the Mueller-Hinton agar (MHA) medium was poured into Petri dishes. Each Petri dish was inoculated with a bacterial inoculum consisting of $0.5 \mathrm{McF}$ arland (1-2) $* 10^{8} \mathrm{CFU} / \mathrm{ml}$. Sterile filter paper discs $(6 \mathrm{~mm}$ diameter) were impregnated with $10 \mu \mathrm{l}$ of the ethanolic pollen extract and then deposited into the medium. Negative control was made using a filter paper disk saturated with $50 \%$ ethanol to check the possible activity of this solvent against the bacteria tested, and standard discs containing antibiotics $(6 \mathrm{~mm})$ were used as a reference control. All Petri dishes were incubated at $37^{\circ} \mathrm{C}$ for 24 hours. After incubation, the zones of inhibition were measured in $\mathrm{mm}$. Each experiment was carried out in triplicate.

2.9.3. Activity Measurement. (2) Minimum Inhibitory Concentration (MIC). The broth microdilution method was used to determine the minimum inhibitory concentration [24]. It was performed by a dilution series of pollen extracts $(0.097$ to $50 \mathrm{mg} / \mathrm{ml}) .10 \mu \mathrm{l}$ of each concentration of this dilution series was mixed in microplate wells with $180 \mu \mathrm{l}$ of Mueller-Hinton broth and $10 \mu \mathrm{l}$ of bacterial inocula at a final microbial concentration of $5 \times 10^{5} \mathrm{CFU} / \mathrm{ml}$. The final volume was $200 \mu \mathrm{l}$, and the concentration of ethanol in each well does not exceed $2.5 \%$. The same percentage of ethanol was used as a negative control; the microplates were cultivated at $37^{\circ} \mathrm{C}$ for $20 \mathrm{~h}$. The bacterial growth was determined after adding $20 \mu \mathrm{l}$ of $0.5 \%$ TTC (2,3,5-triphenyltetrazolium chloride) aqueous solution and incubated for $30 \mathrm{~min}$ at $37^{\circ} \mathrm{C}$ and $120 \mathrm{rpm}$. MIC was defined as the lowest concentration of the extract that inhibited visible growth (showed by the absence of red color after the addition of TTC) [25].

(3) Minimum Bactericidal Concentration (MBC). To determine MBC, a portion from each well $(>$ or $=$ MIC) was subcultured on Muller-Hinton agar (MHA) and incubated at $37^{\circ} \mathrm{C}$ for $24 \mathrm{~h} . \mathrm{MBC}$ was defined as the lowest concentration of the extracts at which the inoculated bacteria were 99.9\% killed. The experiments were done in triplicate.

The antibacterial effect was considered bactericidal or bacteriostatic according to the report MBC/MIC: if $\mathrm{MBC} /$ $\mathrm{MIC}=1-2$, the effect is bactericidal and if $\mathrm{MBC} / \mathrm{MIC}=4$ to 16 , the effect is bacteriostatic [26].

2.10. Statistical Analyses. GraphPad Prism 5 software was used for statistical comparisons using one-way ANOVA, followed by Tukey's multiple comparisons. The level of significance was set at $p<0.05$. Correlations between the parameters studied were achieved by the Pearson correlation coefficient $(r)$. XLSTAT software was used to create heatmaps.

\section{Results and Discussion}

3.1. Antioxidant Content and Activities of Pollen Extracts. The chemical composition and pollen antioxidant activities are enormously varied worldwide and related to plant species and their environmental conditions [27]. Results illustrated in Figure 1 showed wide variability of the polyphenol content between samples. Punica granatum pollen extract had the highest value $(246.07 \pm 2.62 \mathrm{mg} \mathrm{GAE} / \mathrm{g})$, followed by Quercus ilex pollen extract $(146.37 \pm 1.95 \mathrm{mg}$ GAE/g). However, the lowest polyphenol content was recorded in the Centaurium erythraea pollen extract $(21.39 \pm 0.31 \mathrm{mg} \mathrm{GAE} / \mathrm{g})$, which is higher than that reported by Cosmulescu et al. [28] for three Romanian walnut pollen samples ranging between 10.8 and $17.64 \mathrm{mg} \mathrm{GAE} / \mathrm{g}$. Avşar et al. found that the phenolic content of Castanea sativa pollens ranged between $64.02 \pm 0.26$ and $103.8 \pm 6.72 \mathrm{mg}$ GAE/g; these results were higher than those obtained by Centaurium erythraea, Coriandrum sativum, Ruta graveolens, and Citrus aurantium pollen extracts and lower than those found in Quercus ilex and Punica granatum pollen extracts [8].

For flavones/flavonols, Quercus ilex pollen extract presented the highest content $(40 \pm 0.26 \mathrm{mg} \mathrm{QE} / \mathrm{g})$ followed by the Punica granatum pollen extract $(32 \pm 0.9 \mathrm{mgQE} / \mathrm{g})$ and Ruta graveolens pollen extract $(9.78 \pm 1.17 \mathrm{mg}$ QE/g), whereas Citrus aurantium, Centaurium erythraea, and Coriandrum sativum pollen extracts expressed the lowest contents $(6.11 \pm 0.03 \mathrm{mg} \mathrm{QE} / \mathrm{g}, \quad 5.56 \pm 0.13 \mathrm{mgQE} / \mathrm{g}$, and $5.18 \pm 0.26 \mathrm{mgQE} / \mathrm{g}$, respectively). The flavone/flavonol content average of analyzed samples $(86.42 \pm 83.05 \mathrm{mg} \mathrm{QE} /$ g) was higher than that found in three pollen samples harvested from different areas of Romania $(7.98 \pm 0.26 \mathrm{mg}$ QE/g) [28].

Regarding antioxidant ability, it is recommended to be concluded based on multiple antioxidant test models [29-31]. In the present study, the examined extracts were evaluated by four different and complementary methods (TAC, DPPH, ABTS, and RP).

Total antioxidant assay (TAC) is a test carried out at acidic $\mathrm{pH}$. It is based on the reduction of $\mathrm{Mo}(\mathrm{VI})$ to $\mathrm{Mo}(\mathrm{V})$ 


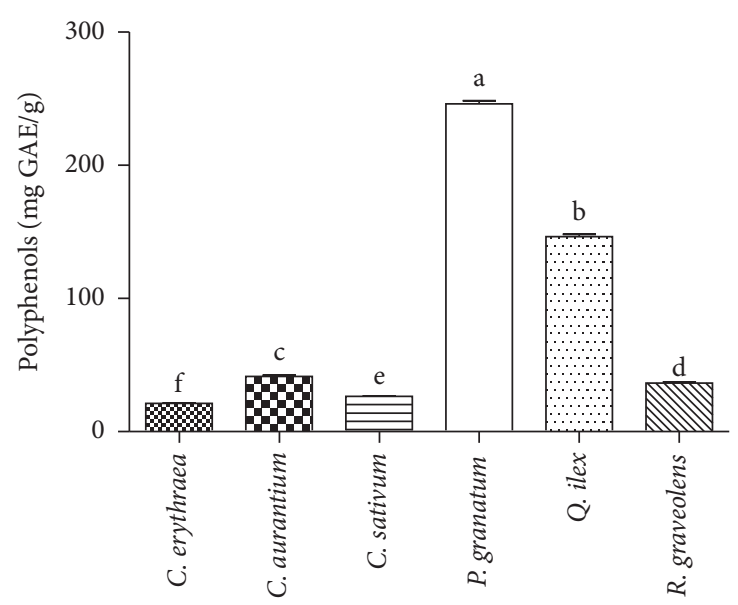

(a)

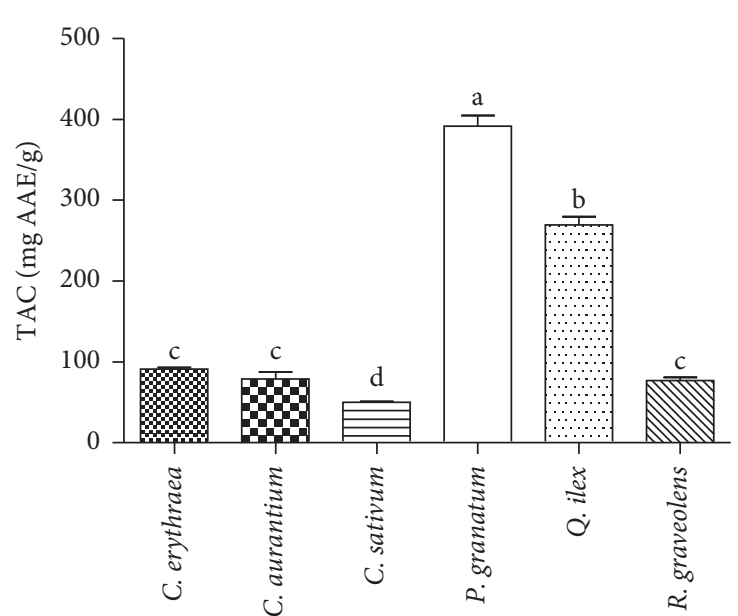

(c)

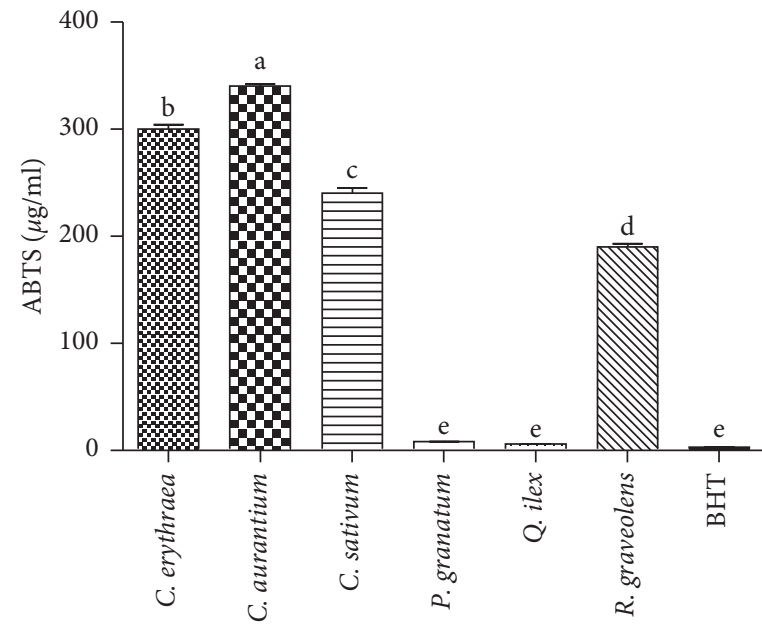

(e)

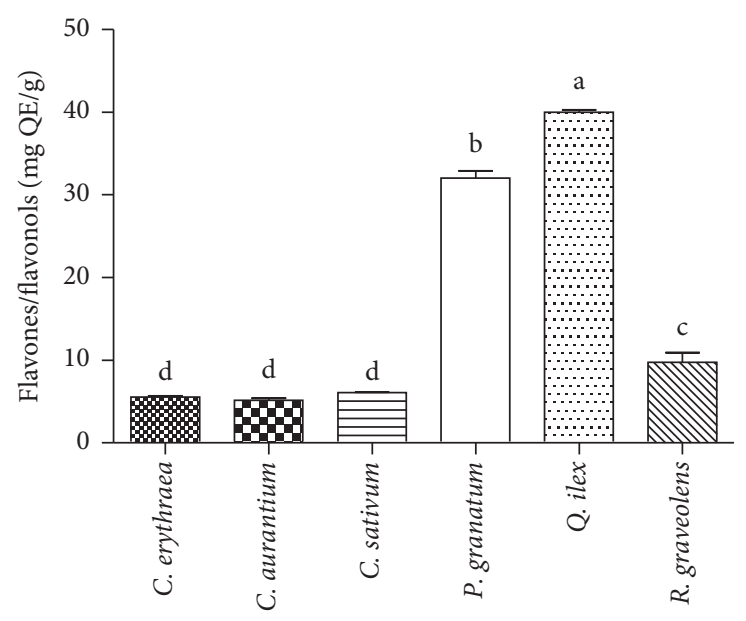

(b)

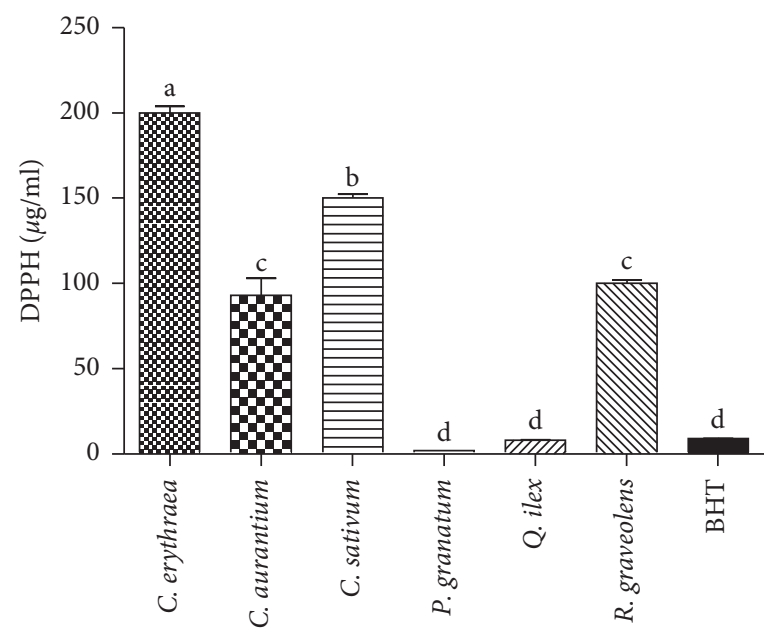

(d)

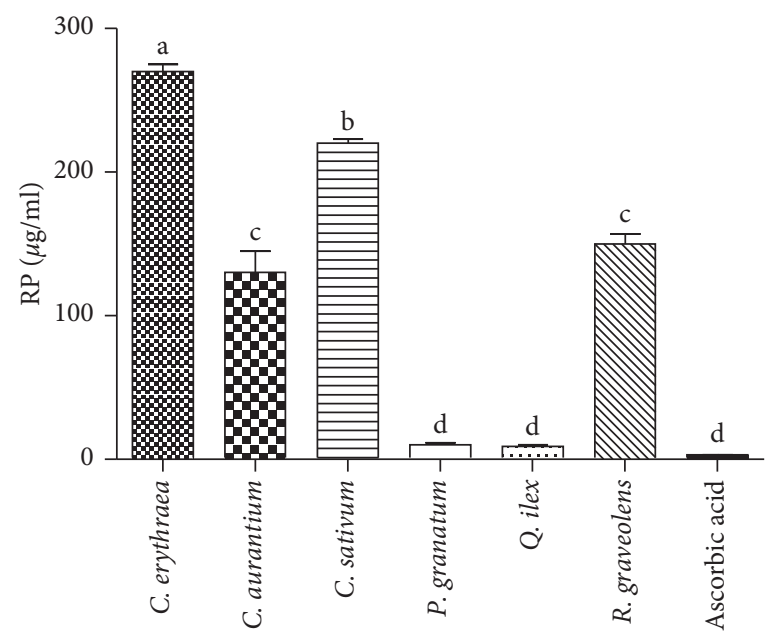

(f)

FIgURE 1: Antioxidant content and antioxidant activities of pollens: (a) the content of polyphenols; (b) the content of flavones/flavonols; (c) the content of total antioxidant capacity (TAC); (d) IC 50 of the DPPH test; (e) IC $\mathrm{I}_{50}$ of the ABTS test; (f) EC En $_{50}$ of reducing power. The results with the same letter in the same test are not significantly different by Tukey's multiple range test $(p<0.05)$; data are the means of three replicates. 
by the analyzed extract and the subsequent formation of a green phosphate/ $\mathrm{Mo}(\mathrm{V})$ complex [32].

Free radical scavenging DPPH is a rapid, easy, economical, and widely used method. It is based on the reduction of purple 2,2-diphenyl-1-picryl-hydrazyl-hydrate $(\mathrm{DPPH} \bullet)$ radical to nonradical yellow-colored diphenylpicrylhydrazine (DPPH-H) in the presence of the hydrogendonating antioxidant $[31,33]$.

The ABTS cation radical assay $\left(\mathrm{ABTS}^{\bullet+}\right)$ is based on the loss of an electron by the nitrogen atom of ABTS $\left(2,2^{\prime}\right.$-azinobis(3-ethylbenzothiazoline-6-sulphonic acid)) following an interaction with the hydrogen-donating antioxidant. In the presence of antioxidant compounds, the nitrogen atom quenches the hydrogen atom, producing solution decolorization [33].

The reducing power method is based on the absorbance increase of the reaction mixture. The antioxidant compounds which have a reducing power react firstly with potassium ferricyanide $\left(\mathrm{Fe}^{3+}\right)$, then with trichloroacetic acid, and finally with ferric chloride to form a colored complex that has an absorption maximum at $700 \mathrm{~nm}$ (ferric-ferrous complex) [29].

The highest total antioxidant capacity was registered in the Punica granatum pollen extract ( $391.47 \pm 13.39 \mathrm{mg}$ AAE/ g) followed by the Quercus ilex pollen extract $(269.97 \pm 9.69 \mathrm{mg} \mathrm{AAE} / \mathrm{g})$. In contrast, the Coriandrum sativum pollen extract presented the lowest antioxidant capacity $(50.35 \pm 0.63 \mathrm{mg} \mathrm{AAE} / \mathrm{g})$, the same has been observed concerning DPPH, ABTS, and RP tests, and Quercus ilex and Punica granatum pollen extracts had the highest antioxidant capacities (DPPH, $\quad \mathrm{IC}_{50}=8 \pm 0.19$ and $2 \pm 0.03 \mu \mathrm{g} / \mathrm{ml}, \mathrm{ABTS}, \mathrm{IC}_{50}=6 \pm 0.3$ and $8 \pm 0.1 \mu \mathrm{g} / \mathrm{ml}$, and $\mathrm{RP}, \mathrm{EC}_{50}=9 \pm 1$ and $10 \pm 1.5 \mu \mathrm{g} / \mathrm{ml}$, respectively). These antioxidant capacities were close to those expressed by BHT and ascorbic acid (Figure 1), while the Centaurium erythraea pollen extract expressed the lowest antioxidant activities (DPPH, $\mathrm{IC}_{50}=200 \pm 3.91 \mu \mathrm{g} / \mathrm{ml}$, ABTS, $\mathrm{IC}_{50}=300 \pm 4 \mu \mathrm{g} / \mathrm{ml}$, and $\left(\mathrm{RP}, \mathrm{EC}_{50}=270 \pm 5 \mu \mathrm{g} / \mathrm{ml}\right)$; these results were better than those reported by Araújo et al. for nine poly- and monofloral bee pollen samples from different localities of Brazil, where the $\mathrm{IC}_{50}$ values of $\mathrm{DPPH}, \mathrm{ABTS}$, and $\mathrm{RP}$ were ranging from $1.94 \pm 0.17$ to $7.99 \pm 0.21 \mathrm{mg} / \mathrm{ml}$, the $\mathrm{IC}_{50}$ values of $\mathrm{ABTS}$ were ranging between $0.91 \pm 0.05$ and $5.73 \pm 0.16 \mathrm{mg} / \mathrm{ml}$, and the $\mathrm{EC}_{50}$ values of $\mathrm{RP}$ were ranging from $1.82 \pm 0.14$ to $8.77 \pm 0.23 \mathrm{mg} / \mathrm{ml}$ [27]. Despite the significant correlation found between the four antioxidant tests (Table 1), it is necessary to highlight that the examined pollen extracts react differently toward each antioxidant assay [34]. For instance, using DPPH and TAC tests, Punica granatum was categorized as the pollen extract with the highest antioxidant activity followed by the Quercus ilex pollen extract, while by ABTS and RP tests, we observed the opposite. Similarly, the pollen extracts identified as having the lowest antioxidant activity were classified depending on the chosen test. For DPPH and RP assays, the lowest activity was displayed by the Centaurium erythraea pollen extract. For the ABTS test, Citrus aurantium pollen extract was categorized as the lowest scavenging activity, while with the TAC test, it was found that the lowest antioxidant activity was registered by Coriandrum sativum. Thus, the hierarchization of pollen extracts depends on the sensitivity of the applied method to discriminate the antioxidant activities of the studied samples [35].

Electron transfer-based assays used in this study are consistent, and conventional methods are used to examine the antioxidant properties of plant extracts and functional foods. However, the acidic condition may affect the effectiveness of the antioxidant activity in pollen; thus, this condition is addressed with a specific assay, namely, CUPRAC (cupric ion reducing antioxidant capacity) method [36]. This assay was also recommended to describe the hydroxyl-based antioxidative capacity for dietary polyphenols $[36,37]$.

3.2. Antibacterial Activity. The antibacterial susceptibility testing was carried out using twenty-eight standard antibiotics; the results obtained were interpreted according to Clinical and Laboratory Standards Institute (CLSI) as susceptible (if the inhibition zone was $\geq 20 \mathrm{~mm}$ ), intermediate (if the inhibition zone was between 15 and $19 \mathrm{~mm}$ ), and resistant (if the inhibition zone was $\leq 14 \mathrm{~mm}$ ) [38]. Following these criteria, it has been concluded from the results presented in Table 2 that Enterobacter cloacae was resistant to amoxicillin + clavulanic acid $\quad(20+10 \mu \mathrm{g} / \mathrm{disc})$ $(12 \pm 0.11 \mathrm{~mm})$, ampicillin $(10 \mu \mathrm{g} / \mathrm{disc})(6 \pm 0 \mathrm{~mm})$, ceftazidime $(30 \mu \mathrm{g} / \mathrm{disc})(6 \pm 0 \mathrm{~mm})$, cefotaxime $(30 \mu \mathrm{g} / \mathrm{disc})$ $(9 \pm 0 \mathrm{~mm})$, cefoxitin $(30 \mu \mathrm{g} / \mathrm{disc})(11 \pm 0.12 \mathrm{~mm})$, cephalothin $(30 \mu \mathrm{g} / \mathrm{disc})(6 \pm 0 \mathrm{~mm})$, gentamicin $(10 \mu \mathrm{g} / \mathrm{disc})$ $(10 \pm 0.54 \mathrm{~mm})$, pefloxacin $(5 \mu \mathrm{g} / \mathrm{disc})(6 \pm 0 \mathrm{~mm})$, ciprofloxacin $(5 \mu \mathrm{g} /$ disc $)(6 \pm 0 \mathrm{~mm})$, nalidixic acid $(30 \mu \mathrm{g} / \mathrm{disc})$ $(6 \pm 0 \mathrm{~mm})$, and trimethoprim + sulfamethoxazole $(1.25+23.75 \mu \mathrm{g} / \mathrm{disc})(6 \pm 0 \mathrm{~mm})$. Escherichia coli was resistant to amoxicillin + clavulanic acid $(20+10 \mu \mathrm{g} / \mathrm{disc})$ $(6 \pm 0 \mathrm{~mm})$ and ampicillin $(10 \mu \mathrm{g} / \mathrm{disc})(6 \pm 0 \mathrm{~mm})$, while Klebsiella pneumoniae was resistant to amoxicillin + clavulanic acid $(20+10 \mu \mathrm{g} / \mathrm{disc})(11 \pm 0 \mathrm{~mm})$ and ampicillin $(10 \mu \mathrm{g} / \mathrm{disc})(6 \pm 0 \mathrm{~mm})$, Staphylococcus aureus was resistant to fusidic acid $(10 \mu \mathrm{g} / \mathrm{disc})(8 \pm 0 \mathrm{~mm})$, and Pseudomonas aeruginosa was resistant to ticarcillin $(75 \mu \mathrm{g} /$ disc) $(11 \pm 0.21 \mathrm{~mm})$, piperacillin $(100 \mu \mathrm{g} / \mathrm{disc})(10 \pm 0 \mathrm{~mm})$, and ceftazidime $(30 \mu \mathrm{g} / \mathrm{disc})(10 \pm 0 \mathrm{~mm})$.

Over the last years, antibiotic resistance has become one of the severe threats to human health. Nowadays, the incurable infections caused by multidrug-resistant bacteria remain among the leading causes of mortality in both developed and developing countries. For this, it is essential to find solutions and to develop new strategies to overcome this phenomenon $[39,40]$. In this context, pollens could represent an appropriate matrix to search for new, safer, and effective antibacterial molecules that can replace or boost the efficiency of conventional antibacterial drugs.

In the present study, ethanolic extracts of pollens were evaluated as natural antibacterial agents against multidrugresistant clinical isolates: Gram-positive (Staphylococcus aureus) and Gram-negative bacteria (Acinetobacter baumannii, Enterobacter cloacae, Escherichia coli, Klebsiella pneumonia, and Pseudomonas aeruginosa). As shown in Table 3, the used 
TABle 1: Pearson correlation coefficients.

\begin{tabular}{|c|c|c|c|c|c|c|}
\hline & Polyphenols & Flavones/flavonols & TAC & $\mathrm{DPPH}$ & ABTS & $\mathrm{RP}$ \\
\hline Polyphenols & & $0.862^{*}$ & $0.989^{* * *}$ & $-0.857^{*}$ & $-0.870^{*}$ & $-0.861^{*}$ \\
\hline Flavones/flavonols & $0.862^{*}$ & & $0.891^{*}$ & $-0.868^{*}$ & $-0.950^{* *}$ & $-0.884^{*}$ \\
\hline TAC & $0.989^{* * *}$ & $0.891^{*}$ & & $-0.827^{*}$ & $-0.878^{*}$ & $-0.840^{*}$ \\
\hline $\mathrm{DPPH}$ & $-0.857^{*}$ & $-0.868^{*}$ & $-0.827^{*}$ & & $0.835^{*}$ & $0.997^{* * *}$ \\
\hline ABTS & $-0.870^{*}$ & $-0.950^{* *}$ & $-0.878^{*}$ & $0.835^{*}$ & & $0.833^{*}$ \\
\hline $\mathrm{RP}$ & $-0.861^{*}$ & $-0.884^{*}$ & $-0.840^{*}$ & $0.997^{* * *}$ & $0.833^{*}$ & \\
\hline Acinetobacter baumannii & 0.765 & $0.911^{*}$ & 0.768 & -0.803 & $-0.979^{* * *}$ & -0.793 \\
\hline Enterobacter cloacae & 0.723 & $0.823^{*}$ & 0.766 & -0.504 & $-0.830^{*}$ & -0.518 \\
\hline Escherichia coli & 0.703 & $0.870^{*}$ & 0.717 & -0.793 & $-0.934^{* *}$ & -0.788 \\
\hline Klebsiella pneumoniae & $0.865^{*}$ & $0.936^{* *}$ & $0.870^{*}$ & -0.797 & $-0.920^{* *}$ & -0.802 \\
\hline Pseudomonas aeruginosa & $0.908^{*}$ & $0.989^{* * *}$ & $0.934^{* *}$ & $-0.864^{*}$ & $-0.932^{* *}$ & $-0.882^{*}$ \\
\hline Staphylococcus aureus & 0.759 & $0.907^{*}$ & 0.750 & $-0.834^{*}$ & $-0.963^{* *}$ & $-0.822^{*}$ \\
\hline
\end{tabular}

Statistical significance, ${ }^{*} p<0.05 ;{ }^{* *} p<0.01 ;{ }^{* * *} p<0.001$.

solvent for pollen extraction (50\% ethanol) did not exert any inhibition diameter on the examined strains as expected. This result was also observed in another study carried out by Akter et al. [41]. However, Centaurium erythraea pollen extract was efficient against Enterobacter cloacae with an inhibition zone of $12 \pm 1 \mathrm{~mm}$, Citrus aurantium pollen extract does not affect all bacterial strains, and Coriandrum sativum pollen extract was efficient against all bacteria except Pseudomonas aeruginosa and Escherichia coli. According to the classification of Ramalhosa et al. [42], Punica granatum and Quercus ilex pollen extracts exhibited a strong antibacterial potential with high inhibition diameter against all tested strains with a remarkable inhibition zone of $19.33 \pm 0.33 \mathrm{~mm}$ and $22.33 \pm 1.20 \mathrm{~mm}$, respectively, against Staphylococcus aureus. However, Ruta graveolens pollen extract was effective against Escherichia coli $(14 \pm 0.57 \mathrm{~mm})$, Acinetobacter baumannii $(13 \pm 0.88 \mathrm{~mm})$, and Staphylococcus aureus $(14 \pm 0.57 \mathrm{~mm})$. The results of the agar disk diffusion method revealed that Staphylococcus aureus (Gram-positive) was more sensitive to the examined pollen extracts than Gram-negative bacterial strains. These results are in line with the results of Velásquez et al. who showed that Gram-positive bacteria are more susceptible than Gram-negative bacteria [43]. This may be due to the difference in the composition of the bacterial wall $[44,45]$. The cytoplasmic membrane of Gram-positive bacteria is particularly rich in anionic phospholipids than that of Gram-negative bacteria, which contributes to the intrinsic resistance of some Gramnegative bacteria to antibiotics. For instance, daptomycin, a lipopeptide antibiotic, is effective against Gram-positive bacteria but is not active against Gram-negative bacteria because of its inability to cross the outer membrane, which is a necessary step for its antibacterial activity [46].

As can be seen from Table 4, all pollen extracts that are effective against bacterial strains present minimum inhibitory concentration (MIC) values ranged between 0.31 and $2.5 \mathrm{mg} / \mathrm{ml}$. The lowest MIC was referred to Punica granatum and Quercus ilex pollen extracts against Acinetobacter baumannii $(0.31 \mathrm{mg} / \mathrm{ml})$ and Staphylococcus aureus $(0.62 \mathrm{mg} / \mathrm{ml})$. At the same time, no antibacterial effect was registered against all bacterial strains treated with the Citrus aurantium pollen extract. Semeniuc et al. [44] showed that MIC values of ethanolic extracts of date palm pollen were ranged between $7.81 \mathrm{mg} / \mathrm{ml}$ for Escherichia coli and $15.6 \mathrm{mg} /$ $\mathrm{ml}$ for Bacillus cereus. These values were higher than those carried out by our extracts.

The minimum bactericidal concentration $(\mathrm{MBC})$ values were also ranged between 0.31 and $2.5 \mathrm{mg} / \mathrm{ml}$ (Table 4), with the lowest minimum bactericidal concentration being expressed by Punica granatum pollen on Acinetobacter baumannii. However, the highest $\mathrm{MBC}$ values were carried out by Centaurium erythraea on Enterobacter cloacae and Coriandrum sativum against all tested strains except Escherichia coli (no effect) and Pseudomonas aeruginosa (no effect), Ruta graveolens on Escherichia coli, and Punica granatum and Quercus ilex pollen extracts against all bacteria except Acinetobacter baumannii and Staphylococcus aureus. Most importantly, among all pollen samples, Punica granatum and Quercus ilex pollen extracts that presented the highest antioxidant potential (Figure 1) displayed better antibacterial activity against Pseudomonas aeruginosa that was found to be resistant against all types of synthetic and natural antibacterial agents [47]. The wide MIC and MBC differences between pollen samples could be attributed to the characteristic of the chemical composition of each pollen in addition to the membrane structure and variable cell wall of examined bacterial strains $[44,48]$.

It has been reported that polyphenols were used as a new strategy to fight bacterial resistance [49]. Several reports have shown that phenolic compounds could be used in combination with antibacterial drugs to potentiate their therapeutic effects or to minimize their side effects [50, 51]. Lin et al. showed that the combination of rifampicin, kaempferol, and quercetin (flavonol compounds) inhibit synergistically $\beta$-lactamase of clinical methicillin-resistant Staphylococcus aureus (MRSA) [52]. Similarly, Liu et al. studied the effect of kaempferol glycosides isolated from Laurus nobilis combined with fluoroquinolones against MRSA, and they found that kaempferol glycosides boost the anti-MRSA effect of fluoroquinolones [53]. Furthermore, $\mathrm{Wu}$ et al. demonstrated that flavonoids (baicalein, chrysin, galangin, kaempferol, luteolin, myricetin, quercetin, tangeritin, and nobiletin) exhibited good antibacterial activities against Escherichia coli via the inhibition of bacterial DNA gyrase [54]. Nawwar et al. showed that Punica granatum 


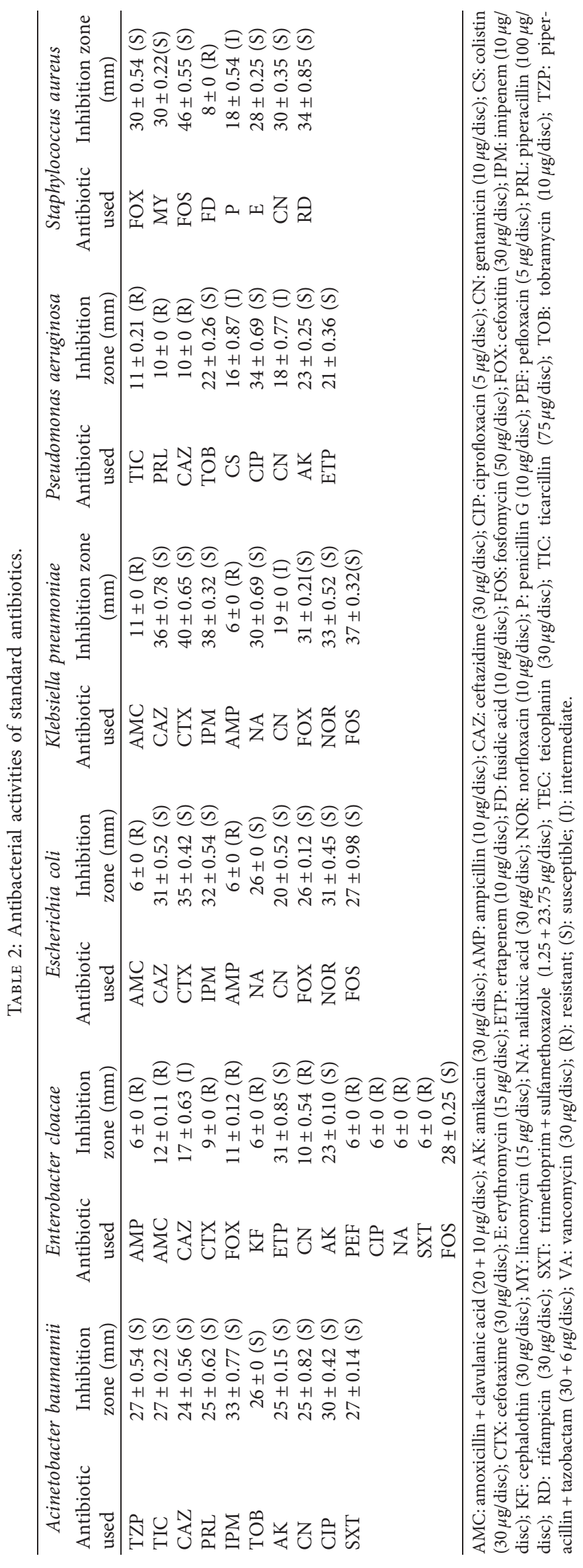


TABLe 3: Antibacterial activities of pollen extracts and ethanol.

\begin{tabular}{|c|c|c|c|c|c|c|}
\hline \multirow[b]{2}{*}{ Pollen samples } & \multicolumn{6}{|c|}{ Mean of the inhibition diameter zone (mm) } \\
\hline & $\begin{array}{c}\text { Acinetobacter } \\
\text { baumannii }\end{array}$ & $\begin{array}{c}\text { Enterobacter } \\
\text { cloacae }\end{array}$ & $\begin{array}{l}\text { Escherichia } \\
\text { coli }\end{array}$ & $\begin{array}{l}\text { Klebsiella } \\
\text { pneumonia }\end{array}$ & $\begin{array}{c}\text { Pseudomonas } \\
\text { aeruginosa }\end{array}$ & $\begin{array}{c}\text { Staphylococcus } \\
\text { aureus }\end{array}$ \\
\hline $\begin{array}{l}\text { Centaurium } \\
\text { erythraea }\end{array}$ & $7 \pm 0.88^{\mathrm{e}}$ & $12 \pm 1^{\mathrm{d}}$ & $7 \pm 1^{e}$ & $6 \pm 0.01^{\mathrm{d}}$ & $6 \pm 0.01^{c}$ & $6 \pm 0.01^{\mathrm{f}}$ \\
\hline Citrus aurantium & $6 \pm 0.01^{\mathrm{e}}$ & $6 \pm 0.01^{\mathrm{f}}$ & $6 \pm 0.01^{\mathrm{f}}$ & $6 \pm 0.01^{\mathrm{d}}$ & $6 \pm 0.01^{c}$ & $7 \pm 1^{e}$ \\
\hline $\begin{array}{l}\text { Coriandrum } \\
\text { sativum }\end{array}$ & $11 \pm 0.18^{\mathrm{d}}$ & $13 \pm 0.57^{c}$ & $8 \pm 0.2^{\mathrm{d}}$ & $11 \pm 0.88^{\mathrm{c}}$ & $6 \pm 0.01^{c}$ & $13 \pm 0.88^{\mathrm{d}}$ \\
\hline Punica granatum & $17 \pm 0.54^{\mathrm{b}}$ & $17 \pm 0.88^{\mathrm{b}}$ & $15 \pm 0.57^{\mathrm{b}}$ & $18.66 \pm 0.88^{\mathrm{b}}$ & $17 \pm 1^{\mathrm{b}}$ & $19.33 \pm 0.33^{\mathrm{b}}$ \\
\hline Quercus ilex & $19 \pm 0.88^{\mathrm{a}}$ & $18 \pm 0.33^{\mathrm{a}}$ & $17.33 \pm 0.88^{\mathrm{a}}$ & $19.66 \pm 0.88^{\mathrm{a}}$ & $18.33 \pm 0.88^{\mathrm{a}}$ & $22.33 \pm 1.20^{\mathrm{a}}$ \\
\hline Ruta graveolens & $13 \pm 0.88^{\mathrm{c}}$ & $8 \pm 0.1^{\mathrm{e}}$ & $14 \pm 0.57^{\mathrm{c}}$ & $6 \pm 0.01^{\mathrm{d}}$ & $6 \pm 0.01^{c}$ & $14 \pm 0.57^{\mathrm{c}}$ \\
\hline Ethanol (control) & $6 \pm 0.01^{e}$ & $6 \pm 0.01^{\mathrm{f}}$ & $6 \pm 0.01^{\mathrm{f}}$ & $6 \pm 0.01^{\mathrm{d}}$ & $6 \pm 0.01^{\mathrm{c}}$ & $6 \pm 0.01^{\mathrm{f}}$ \\
\hline
\end{tabular}

Diameter of the inhibition zone produced around the disks by the addition of $10 \mu \mathrm{l}$ of extracts. Diameter of the disc $=6 \mathrm{~mm}$ is included. All values are represented as the mean of the inhibition zone \pm SD. Values in the same column followed by the same letter are not significantly different by Tukey's multiple range test $(p<0.05)$.

TABLE 4: Minimum inhibitory concentration and minimum bactericidal concentration of pollen extracts.

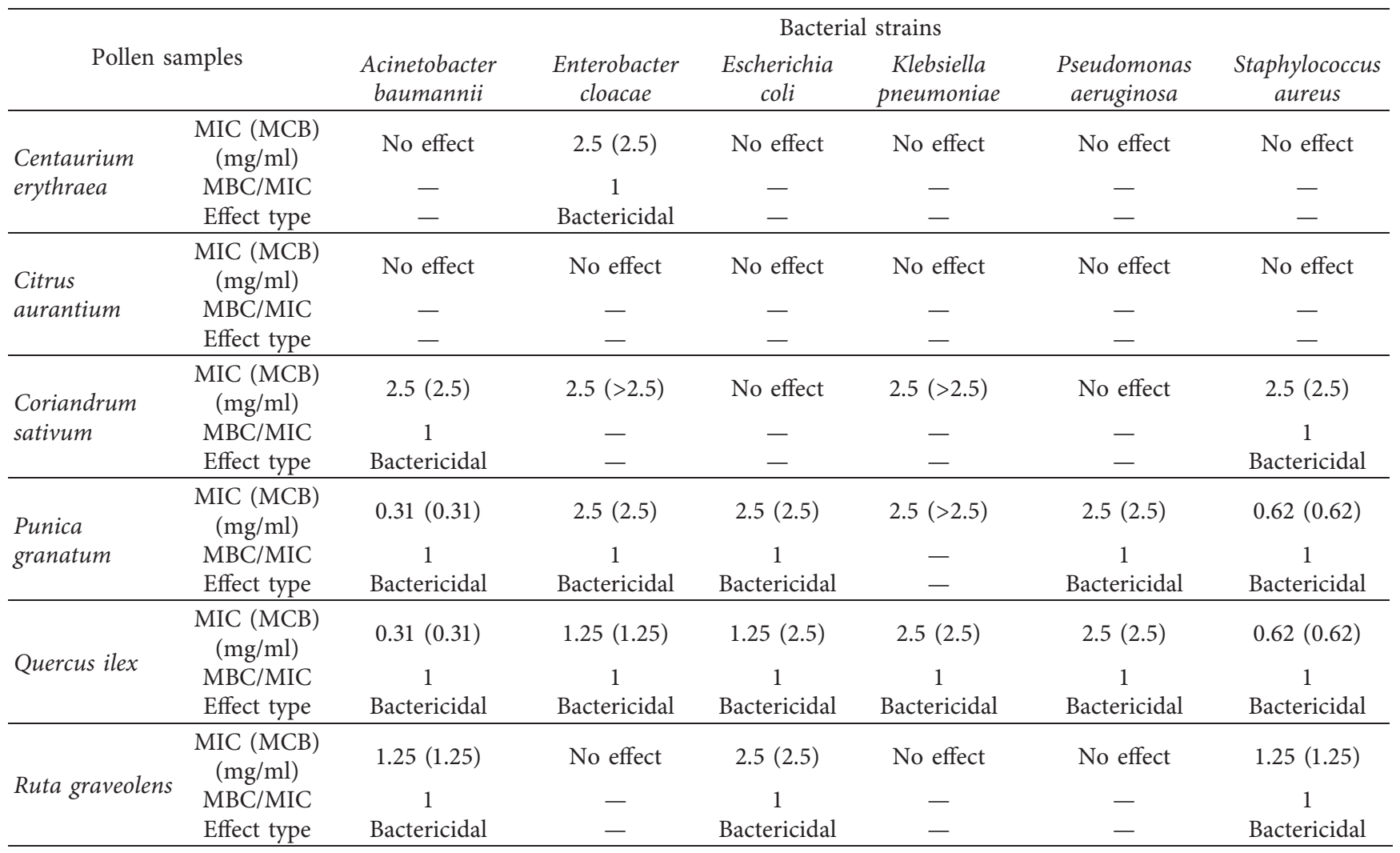

pollen contains several phenolic compounds such as rutin, kaempferol, luteolin, catechin, epicatechin, naringin, and quercetin, which possess potent antibacterial efficacy [55]. Similarly, Han et al. analyzed different parts of Punica granatum (juice, peel, and seeds), and they found 18 polyphenol compounds including cinnamic acid, caffeic acid, gallic acid, protocatechuic acid, ellagic acid, ferulic acid, chlorogenic acid, p-hydroxybenzoic acid, benzoic acid, phloridzin, phloretin, luteolin, punicalagin, catechin, taxifolin, epicatechin, vanillin, and quercetin in which punicalagin and protocatechuic acid were the major components [56]. Likewise, Quercus ilex contains a wide range of polyphenols, including tannin, flavonol, phenolic acid, flavanone, and coumarin compounds [57]. Furthermore, it was found that the main phenolic compounds present in Centaurium erythraea were sinapic acid, $p$-coumaric acid, ferulic acid, and kaempferol [58]. All these arguments support the hypothesis that our samples might contain these bioactive molecules and exert their antibacterial effect through their synergic interactions. 


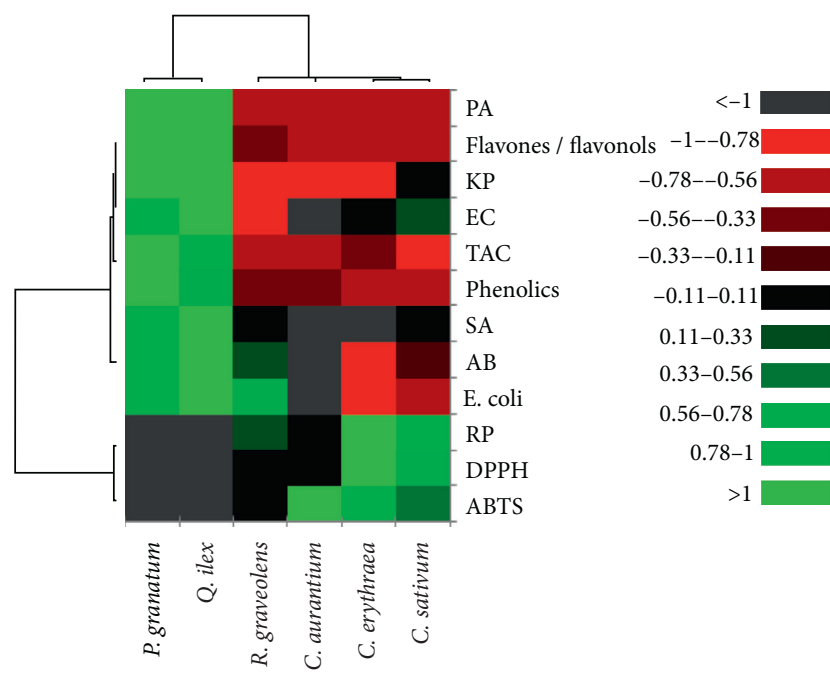

FiguRE 2: Heatmap representation of antioxidant and antibacterial correlations.

3.3. Correlation. The correlation test is considered as a good tool to reveal any relationship between different parameters studied. In the current work, by using the mean values of antioxidant capacity of all pollens tested, we studied the correlation between the antioxidant content and antioxidant activities and between the antioxidant content and antibacterial activities. The outcomes are represented in Table 1. A strong positive relationship between phenolics, flavone/flavonol contents, and the total antioxidant capacity (TAC) was observed. On the contrary, a strong negative correlation was established between bioactive content (phenolic compounds and flavones/flavonols) and antioxidant activity evaluated by TAC, DPPH, ABTS, and RP assays. Results were mainly explained by the high content of bioactive ingredients in pollens. Concerning the relationship between the antioxidant content and antibacterial activities against different strains studied, we found a strong positive correlation between the flavone/flavonol content and the antibacterial activities exerted by different pollen extracts against all bacterial strains. Our findings are in good agreement with previous studies, which showed the correlation relationship between the antioxidant content and antibacterial activity [59-61].

Figure 2 shows the analysis based on the Pearson correlation. Lower concentrations were displayed in black, while higher concentrations were displayed in red color. The heatmap facilitates the task to regroup different samples based on their similitudes. It is observed that the pollen samples have been divided into two groups. One group was composed by Quercus ilex and Punica granatum, while the other group was formed by Centaurium erythraea, Coriandrum sativum, Ruta graveolens, and Citrus aurantium. The heatmap also shows the correlation relationship between the antioxidant content and antioxidant/antibacterial activities.

\section{Conclusion}

This is the first research to report the antioxidant content and the effect of six pollen samples collected from different botanical sources on human multidrug-resistant bacterial strains. The current results indicated that the studied pollen extracts are promising sources of natural antioxidants with potent bactericidal action. The best activities were recorded by Punica granatum and Quercus ilex pollen extracts.

\section{Data Availability}

The data used to support the findings of this study are included within the article.

\section{Conflicts of Interest}

The authors declare that there are no conflicts of interest regarding the publication of this paper.

\section{Acknowledgments}

The authors would like to thank Laboratory (SNAMOPEQ), Faculty of Sciences, Dhar El Mehraz, for providing the facilities to carry out the research work. This study was funded by University Sidi Mohamed Ben Abdellah, P.O. Box 1796, Fez Atlas, Fez, Morocco (USMBA/PPSE/L08FSDM2018).

\section{References}

[1] C. L. Ventola, "The antibiotic resistance crisis: part 1: causes and threats," Pharmacology \& Therapeutics, vol. 40, no. 4, p. 277, 2015.

[2] M. Bakour, N. S. Al-Waili, N. El Menyiy et al., "Antioxidant activity and protective effect of bee bread (honey and pollen) in aluminum-induced anemia, elevation of inflammatory makers and hepato-renal toxicity," Journal of Food Science and Technology, vol. 54, no. 13, pp. 4205-4212, 2017.

[3] A. F. Fihri, N. S. Al-Waili, R. El-Haskoury et al., "Protective effect of Morocco Carob honey against lead-induced anemia and hepato-renal toxicity," Cellular Physiology and Biochemistry, vol. 39, no. 1, pp. 115-122, 2016.

[4] D. Aličić, Š. Drago, M. Jašić, H. Pašalić, and Đ. Ačkar, "Antioxidant properties of pollen," Hrana U Zdr. Boles. Znan.-Stručni Časopis Za Nutr. Dijetetiku, vol. 3, no. 1, pp. 6-12, 2014.

[5] H. M. Hassan, "Chemical composition and nutritional value of palm pollen grains," Global Journal of Biotechnology and Biochemistry, vol. 6, no. 1, pp. 1-7, 2011.

[6] R. Kaur, A. Nagpal, and J. K. Katnoria, "Exploration of antitumor properties of pollen grains of plant species belonging to Fabaceae family," Journal of Pharmaceutical Sciences and Research, vol. 7, no. 3, pp. 127-129, 2015.

[7] N. A. Mohamed, O. M. Ahmed, W. G. Hozayen, and M. A. Ahmed, "Ameliorative effects of bee pollen and date palm pollen on the glycemic state and male sexual dysfunctions in streptozotocin-Induced diabetic wistar rats," Biomedicine \& Pharmacotherapy, vol. 97, pp. 9-18, 2018.

[8] C. Avşar, H. Özler, İ. Berber, and S. Civek, "Phenolic composition, antimicrobial and antioxidant activity of Castanea sativa Mill. pollen grains from Black Sea region of Turkey," International Food Research Journal, vol. 23, no. 4, pp. 1711-1716, 2016.

[9] N. Arslan Burnaz, M. Küçük, and Z. Akar, "An on-line HPLC system for detection of antioxidant compounds in some plant extracts by comparing three different methods," Journal of Chromatography B, vol. 1052, pp. 66-72, 2017. 
[10] N. Sahu, S. Meena, V. Shukla et al., "Extraction, fractionation and re-fractionation of Artemisia nilagirica for anticancer activity and HPLC-ESI-QTOF-MS/MS determination," Journal of Ethnopharmacology, vol. 213, pp. 72-80, 2018.

[11] S. Mushtaq, M. A. Aga, P. H. Qazi et al., "Isolation, characterization and HPLC quantification of compounds from Aquilegia fragrans Benth: their in vitro antibacterial activities against bovine mastitis pathogens," Journal of Ethnopharmacology, vol. 178, pp. 9-12, 2016.

[12] M. M. Elbatanony, A. M. El-Feky, B. A. Hemdan, and M. Azab El-Liethy, "Assessment of the antimicrobial activity of the lipoidal and pigment extracts of Punica granatum L. leaves," Acta Ecologica Sinica, vol. 38, no. 1, pp. 89-94, 2019.

[13] K. Rtibi, I. Hammami, S. Selmi et al., "Phytochemical properties and pharmacological effects of Quercus ilex L. aqueous extract on gastrointestinal physiological parameters in vitro and in vivo," Biomedicine \& Pharmacotherapy, vol. 94, pp. 787-793, 2017.

[14] M. Sefi, H. Fetoui, N. Lachkar et al., "Centaurium erythrea (Gentianaceae) leaf extract alleviates streptozotocin-induced oxidative stress and $\beta$-cell damage in rat pancreas," Journal of Ethnopharmacology, vol. 135, no. 2, pp. 243-250, 2011.

[15] A. F. Begnami, H. M. Spindola, A. L. T. G. Ruiz, J. E. de Carvalho, F. C. Groppo, and V. L. G. Rehder, "Antinociceptive and anti-edema properties of the ethyl acetate fraction obtained from extracts of Coriandrum sativum Linn. leaves," Biomedicine \& Pharmacotherapy, vol. 103, pp. 1617-1622, 2018.

[16] M. Tarique, H. H. Siddiqui, M. Khushtar, and M. A. Rahman, "Protective effect of hydro-alcoholic extract of Ruta graveolens Linn. leaves on indomethacin and pylorus ligation-induced gastric ulcer in rats," Journal of Ayurveda and Integrative Medicine, vol. 7, no. 1, pp. 38-43, 2016.

[17] S.-W. Lim, D.-R. Lee, B.-K. Choi et al., "Protective effects of a polymethoxy flavonoids-rich Citrus aurantium peel extract on liver fibrosis induced by bile duct ligation in mice," Asian Pacific Journal of Tropical Medicine, vol. 9, no. 12, pp. 11581164, 2016.

[18] L. A. Mărghitaş, O. G. Stanciu, D. S. Dezmirean et al., "In vitro antioxidant capacity of honeybee-collected pollen of selected floral origin harvested from Romania," Food Chemistry, vol. 115, no. 3, pp. 878-883, 2009.

[19] M. d. G. Miguel, O. Doughmi, S. Aazza, D. Antunes, and B. Lyoussi, "Antioxidant, anti-inflammatory and acetylcholinesterase inhibitory activities of propolis from different regions of Morocco," Food Science and Biotechnology, vol. 23, no. 1, pp. 313-322, 2014.

[20] G. Zengin, T. Arkan, A. Aktumsek, G. O. Guler, and Y. S. Cakmak, "A study on antioxidant capacities and fatty acid compositions of two Daphne species from Turkey: new sources of antioxidants and essential fatty acids: antioxidant capacity and fatty acid composition," Journal of Food Biochemistry, vol. 37, no. 6, pp. 646-653, 2013.

[21] T. M. S. Silva, F. P. dos Santos, A. Evangelista Rodrigues et al., "Phenolic compounds, melissopalynological, physicochemical analysis and antioxidant activity of jandaíra (Melipona subnitida) honey," Journal of Food Composition and Analysis, vol. 29, no. 1, pp. 10-18, 2013.

[22] P. Padmanabhan and S. N. Jangle, "Evaluation of DPPH radical scavenging activity and reducing power of four selected medicinal plants and their combinations," International Journal of Pharmaceutical Sciences and Drug Research, vol. 4, no. 2, pp. 143-146, 2012.
[23] A. W. Bauer, W. M. Kirby, J. C. Sherris, and M. Turck, "Antibiotic susceptibility testing by a standardized single disk method," American Journal of Clinical Pathology, vol. 45, no. 4, pp. 493-496, 1966.

[24] National Committee for Clinical Laboratory Standards, Document M100-S11. Performance Standards for Antimicrobial Susceptibility Testing, National Committee for Clinical Laboratory Standard, Wayne, PA, USA, 2003.

[25] D. Dimitrijević, "Antioxidant and antimicrobial activity of different extracts from leaves and roots of Jovibarba heuffelii (Schott.) A. Löve and D. Löve," Journal of Medicinal Plants Research, vol. 6, no. 33, 2012.

[26] P. Berche, J. L. Gaillard, and M. Simonet, Les bactéries des infections humaines. Éditeur, Flammarion Médecine \& Sciences, 1991.

[27] J. S. Araújo, E. D. Chambó, M. A. P. d. C. Costa, S. M. P. Cavalcante da Silva, C. A. Lopes de Carvalho, and L. M. Estevinho, "Chemical composition and biological activities of mono- and Heterofloral Bee pollen of different geographical origins," International Journal of Molecular Sciences, vol. 18, no. 5, 2017.

[28] S. Cosmulescu, I. Trandafir, and N. Violeta, "Chemical composition and antioxidant activity of walnut pollen samples," Notulae Botanicae Horti Agrobotanici Cluj-Napoca, vol. 43, no. 2, pp. 361-365, 2015.

[29] Md. N. Alam, N. J. Bristi, and Md. Rafiquzzaman, "Review on in vivo and in vitro methods evaluation of antioxidant activity," Saudi Pharmaceutical Journal, vol. 21, no. 2, pp. 143-152, 2013.

[30] P. Ferreira-Santos, Z. Genisheva, C. Botelho, C. Rocha, and J. A. Teixeira, "Valorization of natural antioxidants for nutritional and health applications," in AntioxidantsIntechOpen, London, UK, 2021.

[31] S. Singh and R. P. Singh, "In vitro methods of assay of antioxidants: an overview," Food Reviews International, vol. 24, no. 4, pp. 392-415, 2008.

[32] P. Prieto, M. Pineda, and M. Aguilar, "Spectrophotometric quantitation of antioxidant capacity through the formation of a phosphomolybdenum complex: specific application to the determination of vitamin E," Analytical Biochemistry, vol. 269, no. 2, pp. 337-341, 1999.

[33] A. M. Pisoschi and G. P. Negulescu, "Methods for total antioxidant activity determination: a review," Biochemistry and Analytical Biochemistry, vol. 1, no. 1, p. 106, 2011.

[34] K. Csepregi, S. Neugart, M. Schreiner, and É. Hideg, "Comparative evaluation of total antioxidant capacities of plant polyphenols," Molecular and Clinical Ophthalmology, vol. 21, no. 2, 2016.

[35] N. Chaves, A. Santiago, and J. C. Alías, "Quantification of the antioxidant activity of plant extracts: analysis of sensitivity and hierarchization based on the method used," Antioxidants, vol. 9, no. 1, p. 76, 2020.

[36] R. Apak, K. Güçlü, B. Demirata, and M. Özyürek, "Comparative evaluation of various total antioxidant capacity assays applied to phenolic compounds with the CUPRAC assay," Molecules, vol. 12, no. 7, pp. 1496-1547, 2007.

[37] B. Bektaşoğlu, S. E. Celik, M. Özyürek, K. Güçlü, and R. Apak, "Novel hydroxyl radical scavenging antioxidant activity assay for water-soluble antioxidants using a modified CUPRAC method," Biochemical and Biophysical Research Communications, vol. 345, no. 3, pp. 1194-1200, 2006.

[38] CLSI, "Performance standards for antimicrobial disk susceptibility tests," Approved Standard-Eleventh Edition. CLSI 
Document M02-A11, Clinical and Laboratory Standards Institute, Wayne, PA, USA, 2012.

[39] J.-P. Lavigne, J. Ranfaing, C. Dunyach-Rémy, and A. Sotto, "Synergistic effect of propolis and antibiotics on uropathogenic Escherichia coli," Antibiotics, vol. 9, 11 pages, 2020.

[40] A. T. B. Abadi, A. A. Rizvanov, T. Haertlé, and N. L. Blatt, "World Health Organization report: current crisis of antibiotic resistance," BioNanoScience, vol. 9, no. 4, pp. 778-788, 2019.

[41] A. Akter, F. A. Neela, M. S. I. Khan, M. S. Islam, and M. F. Alam, "Screening of ethanol, petroleum ether and chloroform extracts of medicinal plants, Lawsonia inermis L. and Mimosa pudica L. for antibacterial activity," Indian Journal of Pharmaceutical Sciences, vol. 72, no. 3, p. 388, 2010.

[42] E. Ramalhosa, T. Delgado, L. Estevinho, and J. Pereira, "Hazelnut (Corylus avellana L.) cultivars and antimicrobial activity," in Nuts and Seeds in Health and Disease Prevention, pp. 627-636, Academic Press, Cambridge, MA, USA, 2011.

[43] P. Velásquez, K. Rodríguez, M. Retamal, A. Giordano, L. Valenzuela, and G. Montenegro, "Relation between composition, antioxidant and antibacterial activities and botanical origin of multi-floral bee pollen," Journal of Applied Botany and Food Quality, vol. 90, pp. 306-314, 2017.

[44] C. A. Semeniuc, C. R. Pop, and A. M. Rotar, "Antibacterial activity and interactions of plant essential oil combinations against Gram-positive and Gram-negative bacteria," Journal of Food and Drug Analysis, vol. 25, no. 2, pp. 403-408, 2017.

[45] T. J. Silhavy, D. Kahne, and S. Walker, "The bacterial cell envelope," Cold Spring Harbor Perspectives in Biology, vol. 2, no. 5, Article ID a000414, 2010.

[46] J. M. Blair, M. A. Webber, A. J. Baylay, D. O. Ogbolu, and L. J. Piddock, "Molecular mechanisms of antibiotic resistance," Nature Reviews Microbiology, vol. 13, no. 1, pp. 42-51, 2015.

[47] E. Lautenbach, M. G. Weiner, I. Nachamkin, W. B. Bilker, A. Sheridan, and N. O. Fishman, "Imipenem resistance among pseudomonas aeruginosa isolates: risk factors for infection and impact of resistance on clinical and economic outcomes," Infection Control \& Hospital Epidemiology, vol. 27, no. 9, pp. 893-900, 2006.

[48] M. Jug, M. Z. Končić, and I. Kosalec, "Modulation of antioxidant, chelating and antimicrobial activity of poplar chemotype propolis by extraction procures," LWT-Food Science and Technology, vol. 57, no. 2, pp. 530-537, 2014.

[49] M. Daglia, "Polyphenols as antimicrobial agents," Current Opinion in Biotechnology, vol. 23, no. 2, pp. 174-181, 2012.

[50] G. Eumkeb, S. Sakdarat, and S. Siriwong, "Reversing $\beta$-lactam antibiotic resistance of Staphylococcus aureus with galangin from Alpinia officinarum Hance and synergism with ceftazidime," Phytomedicine, vol. 18, no. 1, pp. 40-45, 2010.

[51] P. S. Bustos, R. Deza-Ponzio, P. L. Páez et al., "Protective effect of quercetin in gentamicin-induced oxidative stress in vitro and in vivo in blood cells. Effect on gentamicin antimicrobial activity," Environmental Toxicology and Pharmacology, vol. 48, pp. 253-264, 2016.

[52] R.-D. Lin, Y.-P. Chin, W.-C. Hou, and M.-H. Lee, “The effects of antibiotics combined with natural polyphenols against clinical methicillin-resistant Staphylococcus aureus (MRSA)," Planta Medica, vol. 74, no. 8, pp. 840-846, 2008.

[53] M.-H. Liu, N. Otsuka, K. Noyori et al., "Synergistic effect of kaempferol glycosides purified from Laurus nobilis and fluoroquinolones on methicillin-resistant Staphylococcus aureus," Biological and Pharmaceutical Bulletin, vol. 32, no. 3, pp. 489-492, 2009.
[54] T. Wu, X. Zang, M. He, S. Pan, and X. Xu, "Structure-activity relationship of flavonoids on their anti-Escherichia coli activity and inhibition of DNA gyrase," Journal of Agricultural and Food Chemistry, vol. 61, no. 34, pp. 8185-8190, 2013.

[55] M. A. M. Nawwar, S. A. M. Hussein, and I. Merfort, "NMR spectral analysis of polyphenols from Punica granatum," International Journal of Plant Physiology and Biochemistry, vol. 36, no. 3, pp. 793-798, 1994.

[56] L. Han, Z. Yuan, L. Feng, and Y. Yin, "Changes in the composition and contents of pomegranate polyphenols during fruit development," Acta Horticulturae, vol. 1089, pp. 53-61, 2015.

[57] D. Şöhretoğlu and G. Renda, "The polyphenolic profile of Oak (Quercus) species: a phytochemical and pharmacological overview," Phytochemistry Reviews, vol. 19, no. 6, pp. 13791426, 2020.

[58] P. Valentao, E. Fernandes, F. Carvalho, P. Andrade, R. Seabra, and M. Bastos, "Antioxidant activity of Centaurium erythraea infusion evidenced by its superoxide radical scavenging and xanthine oxidase inhibitory activity," Journal of Agricultural and Food Chemistry, vol. 49, no. 7, pp. 3476-3479, 2001.

[59] M. G. de Freitas Araújo, F. Hilário, W. Vilegas et al., "Correlation among antioxidant, antimicrobial, hemolytic, and antiproliferative properties of leiothrix spiralis leaves extract," International Journal of Molecular Sciences, vol. 13, no. 7, pp. 9260-9277, 2012.

[60] D. H. Dinkov, "Correlation between antibacterial and antioxidant activity in oak honeydew and Acacia (Robinia pseudoacacia 1.) bee honeys," in Proceedings of the $V$. International Scientific and Practical Conference on "Current State and Perspectives of Food Industry and Catering Development, Chelyabinsk, Russia, 2013.

[61] V. Todorovic, M. Milenkovic, B. Vidovic, Z. Todorovic, and S. Sobajic, "Correlation between antimicrobial, antioxidant activity, and polyphenols of alkalized/nonalkalized cocoa powders: functional properties of cocoa powder," Journal of Food Science, vol. 82, no. 4, pp. 1020-1027, 2017. 